\title{
Immediate-release Oxymorphone Hydrochloride Liquid Formulation
}

National Cancer Institute

\section{Source}

National Cancer Institute. Immediate-release Oxymorphone Hydrochloride Liquid

Formulation. NCI Thesaurus. Code C116854.

An orally bioavailable, immediate-release (IR), liquid formulation containing the

hydrochloride salt form of oxymorphone, a semisynthetic opioid with potent analgesic

activity. Upon oral administration, oxymorphone binds to and activates opioid receptors,

specifically mu-receptors, in the central nervous system (CNS), thereby mimicking the effects of endogenous opioids and providing analgesia. 